\title{
Effects of Phosphorus Supply on Root Morphology and Phosphorus Uptake in Maize Seedlings under Different Water Regimes
}

\author{
Xinying Chen, Yanjun Gao, Lingjun Hong, Hongliang Tang* \\ College of Life Science, Hebei University, Baoding, P. R. China \\ Email address: \\ xinying.cc@foxmail.com (Xinying Chen), 1535560988@qq.com (Yanjun Gao), 18894493118@163.com (Lingjun Hong), \\ thl_1980@163.com (Hongliang Tang) \\ ${ }^{*}$ Corresponding author
}

\section{To cite this article:}

Xinying Chen, Yanjun Gao, Lingjun Hong, Hongliang Tang. Effects of Phosphorus Supply on Root Morphology and Phosphorus Uptake in Maize Seedlings under Different Water Regimes. American Journal of Agriculture and Forestry. Vol. 8, No. 1, 2020, pp. $22-29$.

doi: 10.11648/j.ajaf.20200801.14

Received: January 4, 2020; Accepted: January 31, 2020; Published: February 11, 2020

\begin{abstract}
Water deficit and phosphorus (P) deficiency in soil have become the main limiting factors for the production of maize (Zea mays L.), but it still remains unclear how water and $\mathrm{P}$ regulate maize root morphology and $\mathrm{P}$ uptake. Through an experiment of potted soil culture, this study has set 4 water gradients [35\% (W1), 55\% (W2), 75\% (W3) and 100\% (W4)] of field capacity, and two P levels [high P: $205 \mathrm{mg}(\mathrm{P}) \cdot \mathrm{kg}^{-1}$; low P: $11 \mathrm{mg}(\mathrm{P}) \cdot \mathrm{kg}^{-1}$ ] to investigate the coupling effects of water and P on root growth and $\mathrm{P}$ uptake in maize seedlings. The results have shown that: (1) Regardless of soil P supply, the shoot dry weight, root dry weight, total root length, and root surface area of maize seedlings shows a trend of increasing first and then decreasing with increasing water supply intensity; the soil available P content also shows similar trend; the root mass ratio and mean root diameter shows a downward trend with the increase of water supply intensity; furthermore, the P content and P accumulation of plants shows a steady increase with the increase of water supply intensity; (2) Water deficit (W1) and excess water supply (W4) is not conducive to root growth and dry matter accumulation in maize. Water deficit (W1) inhibits the acquisition of soil P by maize, while excess water supply (W4) causes extravagant absorption of soil P (W4). Mild water stress (W2) can promote the growth and dry matter accumulation of maize roots and reduce the extravagant absorption of soil $\mathrm{P}$, and adequate water supply (W3) can promote root growth, dry matter accumulation and the absorption of soil P; (3) Phosphorus supply significantly increases the dry weight, root dry weight (except W4), total root length, root surface area, plant P content (except W4) and P accumulation of maize seedlings, but reduces the root mass ratio of maize. It is thus evident that water is a key factor controlling the morphology and accumulation of dry matter in maize roots, and $\mathrm{P}$ is a key factor controlling $\mathrm{P}$ uptake and soil available $\mathrm{P}$ content in corn field. The better coupling between water and $\mathrm{P}$ can promote maize root growth and dry matter accumulation, as well as reduce the extravagant absorption of soil $\mathrm{P}$.
\end{abstract}

Keywords: Water, Phosphorus, Root Morphology, Root Traits, Rhizosphere

\section{Introduction}

As one of the most important nutrient factors, phosphorus is involved in the regulation of many physiological and biochemical reactions in plants and plays a crucial role in plant growth and development [1]. Due to soil fixation, adsorption, complexation, and bioconversion, the bioavailability of phosphorus is low [2]. In order to obtain insoluble phosphorus in soil, plants increase the bioavailability of soil phosphorus by increasing root growth, branching and strengthening rhizosphere effects [3-5]. When the plant absorbs enough phosphorus to have a proper level of phosphorus on the ground, the roots' proliferative response and ability of phosphorus absorption tend to be smaller $[6,7]$.

The bioavailability of soil phosphorus has a close relationship with soil water content. Moisture affects the transport of phosphorus nutrients in soil and the absorption, utilization, and distribution of phosphorus by plants. An 
appropriate level of phosphorus nutrition can, to some extent, improve plant adaptability to drought and water use efficiency $[8,9]$. In recent years, there have been more reports on phosphorus nutrition and water regulation in different crops. In Triticum aestivum, inadequate water supply can strengthen the adverse effects of low-phosphorus stress on tiller number, relative water content in leaf, chlorophyll content and dry matter accumulation, displaying two stress superposition effects [10]. In Vigna aconitifolius, the application of phosphorus fertilizer can significantly alleviate the adverse effects of drought stress on the relative water potential, net photosynthetic rate, chlorophyll content, starch concentration, soluble protein concentration and nitrate reductase activity [11]. In Glycine max, the application of phosphorus fertilizer can improve soybean yield and its resistance to drought stress by improving total root length, root surface area, and phosphorus uptake [12]; but, excessive phosphorus application results in limited yield increase or even yield decrease [13]. In Zea mays, application of phosphorus under sufficient water conditions will lead to extravagant uptake of phosphorus by plants, but will reduce the uptake of soil phosphorus by plants under water deficit conditions [14]. In Bauhinia faberi, phosphorus application promotes plant growth and adaptability under drought stress [15]. From the above studies, it can be seen that the application of phosphorus fertilizer can largely alleviate the adverse effects of water deficit on plant growth, but overdosing phosphorus does not have an obvious alleviation effect, and might even reduce the adaptability of plants to water stress.

There are many reports about effects of water and phosphorus on plant growth and phosphorus uptake, yet they center on the perspectives of dry matter accumulation, phosphorus uptake, and yield production, rather than the perspective of root systems. In this study, maize is used as a research object to study the effects of phosphorus and water on dry matter accumulation, root morphology and phosphorus uptake through potted soil culture experiments, aiming to provide scientific basis for improving the efficient use of water and phosphorus resources in maize.

\section{Materials and Methods}

\subsection{Soil Preparation}

The test soil was collected from the farmland (depth 2 10 $\mathrm{cm}$ ) in the suburbs of Baoding City, Hebei Province, and its type is fluvo-aquic soil. The basal fertility of the soil is as follows: organic carbon, $8.42 \mathrm{~g} \cdot \mathrm{kg}^{-1}$; total nitrogen, 0.85 $\mathrm{g} \cdot \mathrm{kg}^{-1}$; total phosphorus, $0.58 \mathrm{~g} \cdot \mathrm{kg}^{-1}$; available phosphorus (Olsen-P), $5.2 \mathrm{~g} \cdot \mathrm{kg}^{-1}$; alkaline hydrolytic nitrogen, 65.74 $\mathrm{g} \cdot \mathrm{kg}^{-1}$; soil $\mathrm{pH}$ (deionized water), 8.57. The soil bulk density is $1.42 \mathrm{~g} \cdot \mathrm{cm}^{-3}$, and the field capacity is $35 \%$. The air-dried soil is filtered by a $2 \mathrm{~mm}$ sieve to remove plant residue for use.

\subsection{Experiment Design}

The experiment is a completely random design of two factors. Factor A is water set at 4 gradients (W1: field capacity,
35\%; W2: field capacity, 55\%; W3: field capacity, 75\%; W4: field capacity, 100\%). Factor B is phosphorus set at two levels [high phosphorus: $205 \mathrm{mg}(\mathrm{P}) \cdot \mathrm{kg}^{-1}$; low phosphorus: 11 $\left.\mathrm{mg}(\mathrm{P}) \cdot \mathrm{kg}^{-1}\right]$, a total of 8 treatments, 4 replicates per treatment, and a total of 32 pots. The experiment pots are commercially available plastic flower pots (with an inner diameter of $20 \mathrm{~cm}$ at the top, an inner diameter of $16 \mathrm{~cm}$ at the bottom, and a height of $11 \mathrm{~cm}$ ), each containing $3.2 \mathrm{~kg}$ air-dried soil. Excluding phosphorus, other nutrients are added in the following amounts $\left(\mathrm{mg} \cdot \mathrm{kg}^{-1}\right): \mathrm{Ca}\left(\mathrm{NO}_{3}\right)_{2} \cdot 4 \mathrm{H}_{2} \mathrm{O} 1686, \mathrm{~K}_{2} \mathrm{SO}_{4}$ 133, $\mathrm{MgSO}_{4} \cdot 7 \mathrm{H}_{2} \mathrm{O}$ 43.3, Fe-EDTA 5.5, $\mathrm{CuSO}_{4} \cdot 5 \mathrm{H}_{2} \mathrm{O} 2.0$, $\mathrm{MnSO}_{4} \cdot 4 \mathrm{H}_{2} \mathrm{O} \quad 6.6, \quad \mathrm{CaCl}_{2} \cdot 6 \mathrm{H}_{2} \mathrm{O} \quad 125, \mathrm{H}_{3} \mathrm{BO}_{3} \quad 0.67$, $\left(\mathrm{NH}_{4}\right)_{6} \mathrm{MO}_{7} \mathrm{O}_{24} \cdot 4 \mathrm{H}_{2} \mathrm{O} 0.12$, and $\mathrm{ZnSO}_{4} \cdot 7 \mathrm{H}_{2} \mathrm{O}$ 10. The solution of phosphorus in the form of $\mathrm{KH}_{2} \mathrm{PO}_{4}$ is added to the air-dried soil respectively: high phosphorus, $878 \mathrm{mg}\left(\mathrm{KH}_{2} \mathrm{PO}_{4}\right) \cdot \mathrm{kg}^{-1}$ (soil), with a total phosphorus of $199.8 \mathrm{mg} \cdot \mathrm{kg}^{-1}$ (soil); low phosphorus $25 \mathrm{mg}\left(\mathrm{KH}_{2} \mathrm{PO}_{4}\right) \cdot \mathrm{kg}^{-1}$ (soil), with a total phosphorus of $5.7 \mathrm{mg} \cdot \mathrm{kg}^{-1}$ (soil). Potassium for extra phosphorus application is supplemented with $\mathrm{KCl}$ (analytical purity). After potting, the soil water content is maintained at $75 \%$ of the field capacity by weighing.

\subsection{Maize Cultivation}

The experimented maize variety is 'Zhengdan $958^{\prime}$ ', and the seeds were germinated on wet filter paper at $25^{\circ} \mathrm{C}$ for 48 hours after being surface-sterilized with $30 \% \mathrm{H}_{2} \mathrm{O}_{2}$ for 10 minutes. Seeds with uniform germination were selected to sow 3 seeds in per pot. At that time, the soil water content in the pot was controlled to be $75 \%$ of the field capacity. The experiment was conducted in a phytotron under the following conditions: lighting, $16 \mathrm{~h}\left(28^{\circ} \mathrm{C}\right)$; darkness, $8 \mathrm{~h}\left(25^{\circ} \mathrm{C}\right)$; light intensity, 300 $\mu \mathrm{mol} \cdot \mathrm{m}^{-2} \cdot \mathrm{s}^{-1}$; and air humidity, $55 \%$. After maize seedlings germinated, weeds were promptly removed, and the placement of pots was randomly changed every 5 days to minimize the impact of environmental heterogeneity on maize growth. After 7 days of germinating, the pots were weighed on a daily basis by the weighing method (irrespective of plant weight), and the soil water content was calculated every day. After the water content of the potted soil reached the above-mentioned 4 water gradients, the pot weight was weighed at 9:00am every day to replenish the water lost on the day so that the treatments were maintained at the soil water content level corresponding to each treatment. After harvested 40 days later, the biomass, root morphology, plant phosphorus content, and soil available phosphorus content were measured.

\subsection{Measurement Items and Approaches}

Plant harvest: After 40 days of growth, the aboveground part of the shoot was clipped from the base of the maize stem with scissors and put into numbered envelopes. Thereafter, it was used for the measurement of biomass and plant phosphorus content. When the underground part was harvested, the soil first passed through a $2 \mathrm{~mm}$ sieve (the soil through $2 \mathrm{~mm}$ sieve is packed in a plastic valve bag for measuring the available phosphorus content of the soil), and the root systems were collected separately, rinsed, packed in a 
numbered plastic valve bag, and frozen at $20^{\circ} \mathrm{C}$ until root scan analysis.

Biomass measurement: After de-enzymed at $105{ }^{\circ} \mathrm{C}$ for 30 minutes, the aboveground part was dried at $70{ }^{\circ} \mathrm{C}$ for 48 hours to constant weight and then weighed $(\mathrm{g})$; while the underground part was weighed $(\mathrm{g})$ after being dried in the wake of root systems scan to a constant weight. The root mass ratio (\%) was calculated according to formula [root mass ratio $=$ root dry weight $/$ (seedling dry weight + root dry weight $) \times$ $100 \%]$.

Measurement of plant phosphorus content: The dried aboveground part was ground into powder $(<0.5 \mathrm{~mm})$ and digested with $\mathrm{H}_{2} \mathrm{SO}_{4}-\mathrm{H}_{2} \mathrm{O}_{2}$. The phosphorus concentration of the decontamination liquid was determined by vanadium molybdenum yellow colorimetry. The plant phosphorus content $\left(\mathrm{mg} \cdot \mathrm{g}^{-1}\right)$ is the milligrams $(\mathrm{mg})$ of phosphorus in per gram (g) of plant dry weight; the phosphorus accumulation is the phosphorus content $\left(\mathrm{mg} \cdot \mathrm{g}^{-1}\right)$ multiplied by the dry weight of plants $(\mathrm{g})$.

Measurement of root morphological parameters: In order to obtain the root morphological parameters of maize, the frozen roots were slowly thawed and then subjected to a root system scan on a double-sided scanner (Epson Expression v750, Japan). The scanned root system images were directly analyzed by WinRHIZO Image Analysis System (WinRHIZO Pro 2009) for total root length (cm), root surface area $\left(\mathrm{cm}^{2}\right)$ and mean root diameter $(\mathrm{mm})$.

Measurement of available phosphorus content in soil: After roots were collected, the soil was leached with $\mathrm{NaHCO}_{3}$, and molybdenum antimony colorimetry was used to measure the available phosphorus content of the soil [16].

\subsection{Data Analysis}

Statistical data analysis was performed by SPSS 13.0 (SPSS Inc, 2004, USA). The independent sample $t$-test was applied to test the significant differences between the two different phosphorus treatments for individual study indicators. After significant test of one-way ANOVA, Tukey HSD method was employed to test the significant differences between different water supply treatments; moreover, two-way ANOVA was adopted to test the effects of water, phosphorus, and their interactions on dry matter accumulation, root morphology, phosphorus uptake, and soil available phosphorous in maize.

\section{Results and Analysis}

\subsection{Coupling Effects of Water and Phosphorus on Biomass Accumulation and Distribution in Maize}

As can be seen from Figure 1, phosphorus supply significantly increases shoot dry weight and root dry weight (except for W4 water supply), but decreases root mass ratio $(P<0.05)$. Under the condition of low phosphorus supply, the shoot dry weight and root dry weight of maize show an increasing trend with the increase of water supply intensity; W3 water supply enables maize to obtain the maximum shoot dry weight and root dry weight at the same time, but W4 water supply reduces the root dry weight. Under the condition of high phosphorus supply, the shoot dry weight and root dry weight of maize first increase and then decrease as the water supply intensity increases; W2 enables maize to obtain the maximum shoot dry weight and root dry weight at the same time, but, W4 water supply reduces the shoot dry weight and root dry weight to some extent (Figure 1a, b). Compared with shoot dry weight and root dry weight, the root mass ratio shows a decreasing trend with the increase of water supply intensity. Under the condition of low phosphorus supply, W1 water supply gives the maize a maximum root mass ratio, and $\mathrm{W} 2, \mathrm{~W} 3$, and $\mathrm{W} 4$ water supplies have the same root mass ratio. Under the condition of high phosphorus supply, W1 water supply maximizes the root mass ratio likewise, whereas W3 and W4 water supplies result in a minimum root mass ratio (Figure 1c). Two-way ANOVA shows that phosphorus and water exert enormous effects on shoot dry weight, root dry weight, and root mass ratio of maize seedlings, and that there is a striking interaction effect between phosphorus and water $(P<0.05$, Table 1$)$. The relative contributions of water supply to shoot dry weight, root dry weight and root mass ratio are $45.94 \%, 36.71 \%$ and $54.89 \%$ respectively, and those of phosphorus supply are $34.78 \%, 21.19 \%$ and $14.84 \%$.
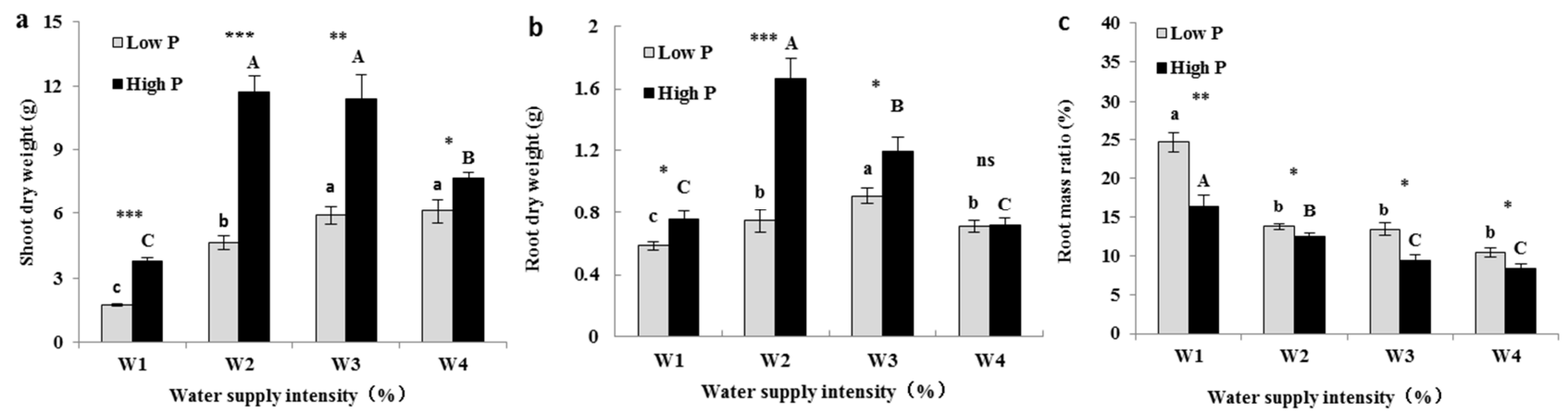

Figure 1. Effects of water and phosphorus supplies on dry matter accumulation and allocation in maize.

Note: $\mathrm{W} 1, \mathrm{~W} 2, \mathrm{~W} 3$ and $\mathrm{W} 4$ mean soil water contents are $35 \%$, $55 \%, 75 \%$ and $100 \%$ of field capacity, respectively. $*, * *$ and *** denote significant difference at $P<0.05, P<0.01$ and $P<$ 0.001 levels between two phosphorus treatments; ns denotes no significant difference between two phosphorus treatments. Different letters denote significant difference at $P<0.05$ level among different water supply intensity treatments. The same below. 


\subsection{Coupling Effects of Water and Phosphorus on Maize Root Morphology}

As can be seen from Figure 2, phosphorus supply significantly increases the total root length and root surface area of maize $(P<0.05)$. Except for W2 water supply, phosphorus produces no marked effect on mean root diameter $(P>0.05)$. Under the condition of low phosphorus supply, the total root length and root surface area demonstrate a trend of increasing first and then decreasing with the increase of water supply intensity; W2 and W3 water supplies lead to maximum total root length and root surface area at the same time; and, W4 water supply lessens total root length and root surface area. Under the condition of high phosphorus supply, the total root length and root surface area similarly increase first and then decrease with increasing water supply intensity; W2 water supply results in maximum total root length and root surface area at the same time; and, W3 and W4 water supplies lower total root length and root surface area
(Figure 2a, b). Vis-a-vis total root length and root surface area, the mean root diameter of maize exhibits a decreasing trend as the water supply intensity increases. Under the condition of low phosphorus supply, W1 water supply gives maize a maximum mean root diameter, and W3 and W4 water supplies have the same mean root diameter. Under the condition of high phosphorus supply, W1 water supply also enables maize to gain a maximum root mass ratio, and $\mathrm{W} 2, \mathrm{~W} 3$, and $\mathrm{W} 4$ water supplies have the same mean root diameter (Figure 2c). As Two-way ANOVA indicates, water creates a considerable effect on total root length, root surface area, and mean root diameter; phosphorus exerts a significant effect on total root length and root surface area; moreover, both water and phosphorous achieve substantial interaction effects on total root length and root surface area $(P<0.05$, Table 1$)$. The relative contributions of water supply to total root length, root surface area, and mean root diameter are $59.63 \%, 58.34 \%$, and $81.86 \%$ respectively, and those of phosphorus supply are $9.22 \%, 9.21 \%$ and $1.56 \%$.
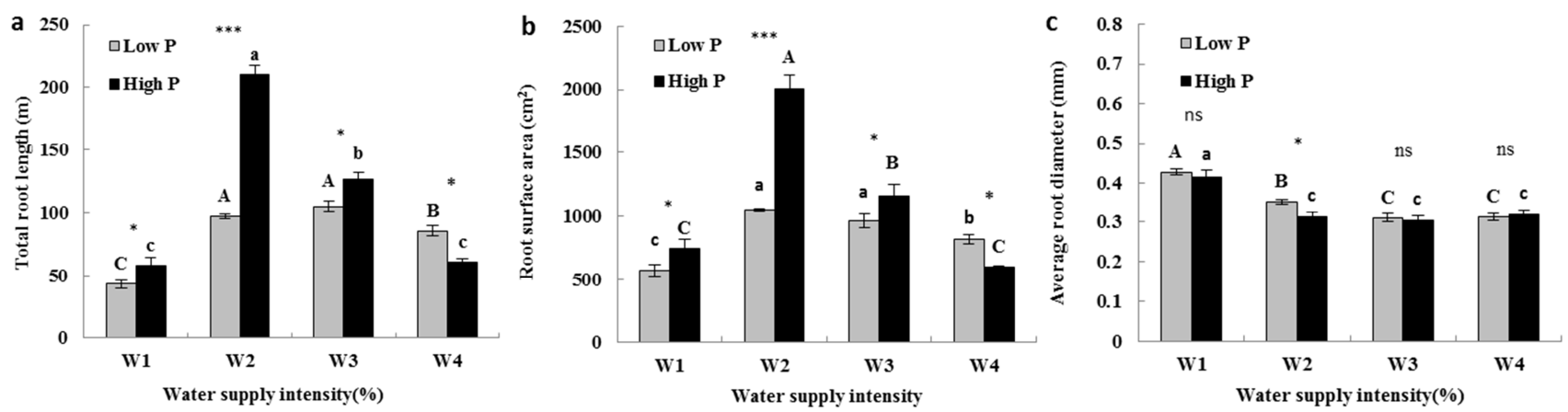

Figure 2. Effects of water and phosphorus supplies on root morphology in maize.

\subsection{Coupling Effects of Water and Phosphorus on Phosphorus Content and Phosphorus Accumulation in Maize Plants}

As can be seen from Figure 3, phosphorus supply considerably raises the phosphorus content (except for W4 water supply) and phosphorus accumulation $(P<0.05)$ in maize plants. Under the condition of low phosphorus supply, with the increase of water supply intensity, the phosphorus content and phosphorus accumulation display a trend of increasing first and then decreasing, and W1 water supply results in minimum phosphorus content and phosphorus accumulation at the same time. Under the condition of high phosphorus supply, with the increase of water supply intensity, both phosphorus content and phosphorus accumulation indicate an increasing trend, and W4 water supply leads to maximum phosphorus content and phosphorus accumulation at the same time (Figure 3a, b). Owing to differences in shoot dry weight, W3 and W4 water supplies have the same amount of phosphorus accumulation (Figure 3b). Two-way ANOVA suggests that phosphorus and water produce significant effects on phosphorus content and phosphorus accumulation in maize plants, and there is a significant interaction effect between the two $(P<0.05$, Table 1$)$. The relative contributions of water supply to plant phosphorous content and phosphorous accumulation are $24.75 \%$ and $35.66 \%$ respectively, and those of phosphorous supply are $35.54 \%$ and $49.75 \%$ severally.
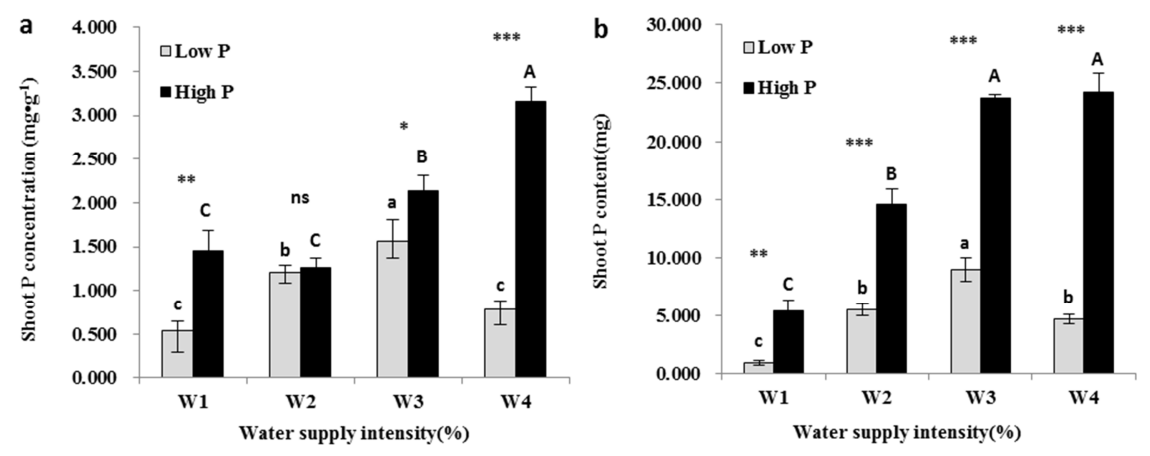

Figure 3. Effects of water and phosphorus supplies on shoot P content and accumulation in maize. 


\subsection{Effects of Water Content and Phosphorus Supply on Available Phosphorus Content in Soil}

As can be seen from Table 2, the change of soil available phosphorus content depends on the intensity of water supply and the amount of phosphorus applied. Under the condition of low phosphorus supply, the available phosphorus content of soil shows a trend of increasing first and then decreasing, however there is no significant statistical difference between the four soil moisture treatments. Under the condition of high phosphorus supply, the soil available phosphorus content shows a similar trend of increasing first and then decreasing with the increase of soil water supply intensity, and W2 water supply intensity has the highest soil available phosphorus content, which is followed by W3, and W1 and W4 have the lowest available phosphorus content. Two-way ANOVA displays that phosphorus and water produce significant effects on soil available phosphorus content, and there is a significant interaction effect between the two $(P<0.01$, Table 1). The relative contribution of water supply to soil available phosphorus is $94.4 \%$, and that of phosphorus supply is $3.0 \%$.

Table 1. Two-way analysis of variance for the effects of water and phosphorus supplies on dry matter accumulation, root morphology and phosphorus uptake.

\begin{tabular}{|c|c|c|c|c|c|c|c|c|c|c|}
\hline \multirow[b]{3}{*}{ Parameter } & \multicolumn{9}{|c|}{ Sources of variation } & \multirow[b]{3}{*}{$R^{2}$} \\
\hline & \multicolumn{3}{|l|}{ Water } & \multicolumn{2}{|c|}{ Phosphorus } & & \multicolumn{3}{|c|}{ Water $\times$ phosphorus } & \\
\hline & $F$ value & $\begin{array}{l}P \\
\text { value }\end{array}$ & $\begin{array}{l}\text { Relative } \\
\text { contribution to } \\
\text { the total } \\
\text { variance }(\%)\end{array}$ & $F$ value & $P$ value & $\begin{array}{l}\text { Relative } \\
\text { contribution to } \\
\text { the total } \\
\text { variance }(\%)\end{array}$ & $F$ value & $\begin{array}{l}P \\
\text { value }\end{array}$ & $\begin{array}{l}\text { Relative } \\
\text { contribution to } \\
\text { the total } \\
\text { variance }(\%)\end{array}$ & \\
\hline Shoot dry weight & 47.47 & $<0.01$ & 45.94 & 107.81 & $<0.01$ & 34.78 & 11.92 & $<0.01$ & 11.54 & 0.92 \\
\hline Root dry weight & 14.36 & $<0.01$ & 36.71 & 24.86 & $<0.01$ & 21.19 & 8.46 & $<0.01$ & 21.64 & 0.80 \\
\hline Total root length & 70.09 & $<0.01$ & 59.63 & 32.50 & $<0.01$ & 9.22 & 28.61 & $<0.01$ & 24.34 & 0.93 \\
\hline Root surface area & 45.12 & $<0.01$ & 58.34 & 21.36 & $<0.01$ & 9.21 & 17.10 & 0.00 & 22.11 & 0.90 \\
\hline $\begin{array}{l}\text { Average root } \\
\text { diameter }\end{array}$ & 47.74 & $<0.01$ & 81.86 & 2.74 & 0.11 & 1.56 & 1.66 & 0.20 & 2.85 & 0.86 \\
\hline $\mathrm{P}$ content & 15.98 & $<0.01$ & 24.75 & 68.84 & $<0.01$ & 35.54 & 17.64 & $<0.01$ & 27.32 & 0.88 \\
\hline $\mathrm{P}$ accumulation & 86.17 & $<0.01$ & 35.66 & 360.60 & $<0.01$ & 49.75 & 27.24 & $<0.01$ & 11.28 & 0.97 \\
\hline $\begin{array}{l}\text { Soil available P } \\
\text { content }\end{array}$ & 13.91 & $<0.01$ & 3.00 & 1333.39 & $<0.01$ & 94.4 & 12.43 & $<0.01$ & 2.6 & 0.98 \\
\hline
\end{tabular}

Table 2. Effect of water and phosphorus on soil available phosphorus content.

\begin{tabular}{lll}
\hline Water supply intensity & P supply & Available P content $\left(\mathbf{m g} \cdot \mathbf{k g}^{-\mathbf{1}}\right)$ \\
\hline \multirow{2}{*}{ W1 } & Low $\mathrm{P}$ & $3.16 \pm 0.64 \mathrm{~A}$ \\
& High P & $69.06 \pm 3.27 \mathrm{c}$ \\
W2 & Low P & $3.78 \pm 0.68 \mathrm{~A}$ \\
& High P & $96.32 \pm 5.43 \mathrm{a}$ \\
W3 & Low P & $3.54 \pm 0.59 \mathrm{~A}$ \\
& High P & $83.19 \pm 4.22 \mathrm{~b}$ \\
W4 & Low P & $3.44 \pm 0.52 \mathrm{~A}$ \\
& High P & $63.65 \pm 2.49 \mathrm{c}$ \\
\hline
\end{tabular}

\section{Conclusion and Discussion}

As the main organ for absorbing water and nutrients, the root system plays an important role in the growth, yield, quality formation, and nutrient uptake of the aboveground part In the early stage of water and nutrient deficit, plants tend to develop deeper, larger root systems, and increase the length of roots and the distribution of dry matter to the ground to cope with the dual stress caused by water and nutrients; yet in the later stage of stress, this favorable adaptability of the root system is inclined to disappear [9]. In this study, in the later stages of water deficit (W1 moisture treatment) and low phosphorus stress (except W4 water supply) (Figure 1b; Figure $2 \mathrm{a}, \mathrm{b}$ ), the root dry weight, total root length, and root surface area of maize demonstrate a significant decrease, while the root mass ratio exhibits a marked increase (Figure 1c), which is consistent with the results reached by Hermans et al. [17] and Songsri et al. [18].

The beneficial effect of phosphorus application on maize root growth relies to a large extent on water supply. Jin et al. [12] carried out field trials of two soybean varieties and found out that: under the condition of severe water stress $(65 \% \sim 75 \%$ of field capacity), phosphorus supply substantially increased the total root length and root surface area of 'Denglong 46', but its increase in 'Heisheng101' was small; under the condition of adequate water supply $(65 \% \sim 75 \%$ of field capacity), the phosphorus supply markedly increased the total root length and root surface area of the two soybean varieties, indicating that soil moisture status can regulate the response of different soybean genotypes to phosphorus supply. In this study, under conditions of severe water stress (W1) and adequate water supply (W3), phosphorus supply observably increases total root length and root surface area (Figure 2a, b), which is identical to the results of the study conducted by Jin et al. [12] on the soybean variety of "Denglong 46". According to the study on seedling maize by Zhao et al. [14], adequate water supply ( $75 \%$ of field capacity) and excess water supply $(90 \%$ of field capacity) under potting conditions notably enhance the root dry weight of maize. In this study, adequate water supply (W3) prominently increases the root dry weight of maize, and excess water supply (W4) has no significant effect on the dry root weight of maize (Figure 1b). The possible reason for the difference lies in different water supply intensity: the excess water supply used by Zhao et al. [14] is $90 \%$ of field capacity, whereas that in this study is $100 \%$ of field capacity. In 
addition, it should be mentioned that, under the condition of mild water stress (W2), the favorable effect of phosphorus on total root length and root surface area of maize is fully reflected; but, under the condition of excess water supply (W2), phosphorus supply has a negative effect on total root length and root surface area (Figure 2a, b). The positive or negative response of the maize root system to phosphorus supply is related to soil aeration caused by soil water content. Present studies have shown that when the soil oxygen concentration is lower than $10 \mathrm{mg} \cdot \mathrm{L}^{-1}$, the roots will stop growing [19]. In this study, mild water stress treatment (W2) has good soil aeration, adequate oxygen, and smooth root respiration, and phosphorus has a significant stimulatory effect on the root system of maize, resulting in a significant increase in total root length and root surface area. Most soil pores in excess water supply treatment (W4) are saturated with moisture and thus poor ventilation, root respiration is likely to be inhibited, and phosphorus has a negative effect on total root length and root surface area of maize. Apart from total root length and root surface area, root diameter acts a very critical role in the acquisition of soil phosphorus. The root diameter reflects the fineness of the root, the smaller the root diameter, the finer the root, which determines the absorption of water and nutrients by the root system [20, 21]. In this study, regardless of phosphorus supply, maize grown under the condition of water deficit (W1) has the largest mean root diameter (Figure 2c), indicating thicker root system, which greatly reduces the uptake of soil phosphorus by maize root systems, but enhances the ability of the root system to withstand the adverse environment. It can be seen that water supply exerts a significant impact on the growth and development of maize root systems and the absorption of phosphorus.

Moisture can not only directly affect the growth and development of plant roots, but also indirectly impact the plant root morphology and phosphorus uptake by affecting the soil available phosphorus content and phosphorus form. Previous studies have shown that soil water supply can significantly increase concentrations of available phosphorus [22] and aluminum-phosphorus (AI-P) in reddish paddy soil, but no marked effect on concentrations of soil organic phosphorus, iron-phosphorus (Fe-P), calcium-phosphorus (Ca-P), and occluded phosphorus (Oc-P) [23]. The concentration of available phosphorous in paddy soil under flooding conditions ( $100 \%$ of field capacity) is notably higher than that under aerobic conditions ( $60 \%$ of field capacity); moreover, with the increase of soil phosphorous supply, the difference between available phosphorus content in soil under two water supply conditions reflects a trend of massive increase [24]. In this study, under the condition of high phosphorus, the available phosphorus content in soil first increases and then decreases with increasing water supply intensity, and W2 water supply intensity has the highest available phosphorus content. Under the condition of low phosphorus, as water supply intensity increases, the available phosphorus content in soil exhibits a trend similar to that under the condition of high phosphorus, but there is no substantial statistical difference of soil available phosphorus content between the four moisture treatments (Table 2), which was inconsistent with previous studies [22-24] and may be related to soil varieties and cultivated crop species. Under the water supply intensity of W2, maize has observably larger root length and root surface area, which, on the one hand, can enhance the chance of the root system capturing phosphorus in soil, and on the other, can utilize root-secreted organic acid to activate insoluble soil phosphorus and secreted acid phosphatase to mineralize soil organic phosphorus, which results in higher soil available phosphorus content. He et al. [23] discovered that, with the increase of water supply intensity, the available phosphorus content in soil increased significantly, but the organic phosphorus content did not change greatly. Based on that, this study speculates that under W2 water supply intensity, the increase of soil available phosphorus content derives more from the activation of soil insoluble phosphorus by root exudates, and less from the mineralization of organic phosphorus. In this study, the trend of soil available phosphorus content increasing first and then decreasing with water supply intensity is basically the same as that of maize root length (Figure 2a) and root surface area (Figure 2b), but distinct from that of plant phosphorus content and phosphorus accumulation, implying that the increase in soil available phosphorus content produces a substantial stimulatory effect on the growth of maize roots (this is especially evident under the condition of high phosphorus supply); furthermore, water supply occupies a considerable role in promoting phosphorus uptake in maize.

Previously, the regulation of water and phosphorus on plant growth has been mainly concentrated on crops such as Triticum aestivum [10], Vigna aconitifolius [11], Glycine max $[12,14]$, and Zea mays [13], but the relative importance of water and phosphorus has been rarely or only qualitatively described. In order to further investigate the importance of water and phosphorus in maize roots, this study has calculated the relative contributions of water and phosphorus to maize root morphological parameters based on the two-way ANOVA. The relative contributions of water to root dry weight, total root length, root surface area, and mean root diameter are $36.71 \%, 59.63 \%, 58.34 \%$, and $81.86 \%$ respectively, and those of phosphorus are $21.19 \%, 9.22 \%$, $9.21 \%$, and $1.56 \%$ severally. In this way, moisture is a key factor controlling the growth of maize roots, followed by phosphorus. This is consistent with the study carried out by Jin et al. [12] and Zhao Changhai et al. [14]. These results provide a scientific basis for reasonable regulation on water phosphorus.

Phosphorus in soil, with poor mobility and low diffusion rate, is easily adsorbed and fixed. The acquisition of phosphorus by roots is more dependent on the change of root morphology $[3,8]$. As a result, relatively long root system with large surface area and many branches can occupy more soil volume, increase the contact area with soil phosphorus, and have obvious advantages in the acquisition of soil phosphorus. In this study, maize roots adopt two different strategies for the acquisition of soil phosphorus due to the 
difference in soil phosphorus and water supply intensity. Under the condition of low phosphorus, regardless of water supply, maize plants with higher root dry weight, total root length, and root surface area receive relatively more soil phosphorus, indicating that changes in root morphology are crucial for soil phosphorus acquisition. At this time, the acquisition of soil phosphorus by maize takes a root-based adaptation strategy [25]; Under the condition of high phosphorus, regardless of root morphology, the phosphorus content and phosphorus accumulation in maize plants gradually increases with the increase of water supply intensity (Figure 3a, b), indicating that moisture is crucial for soil phosphorus acquisition. At this time, the acquisition of soil phosphorus by maize takes an adaptation strategy based on root physiological absorption [25]. The maize grown under conditions of high phosphorous and mild water stress (W2) has the largest root dry weight, total root length, and root surface area; yet, due to the input of more carbon sources for root growth, the physiological absorption of phosphorus by root systems becomes weak, and the phosphorus obtained is significantly lower than that of maize grown under conditions of adequate and excess water supply. In terms of the maize grown under conditions of high phosphorus and excess water supply (W4), in spite of poor soil aeration and lower root dry weight, total root length, and root surface area, the physiological absorption of phosphorus by the root system is stronger, thus gaining more soil phosphorus.

\section{References}

[1] Schachtman D P, Reid R J, Ayling S M (1998). Phosphorus uptake by plants: From soil to cell. Plant Physiology, 116: 447-453.

[2] Holford I C R (1997). Soil phosphorus: Its measurement, and its uptake by plants. Australian Journal of Soil Research, 35: 227-239.

[3] Vance C P, Uhde-Stone C, Allan D L (2003). Phosphorus acquisition and use: critical adaptations by plants for securing a nonrenewable resource. New Phytologist, 157: 423-447.

[4] Hinsinger P, Bengough A G, Vetterlein D, Young I M (2009). Rhizosphere: biophysics, biogeochemistry and ecological relevance. Plant and Soil, 321: 117-152.

[5] Su J, Zhang W J, Du L, et al. (2014). Effects of sucrose on rice root adaptability and phosphate transporter gene expression under phosphorus stress. Chinese Journal of Eco-Agriculture, 22 (11): 1334-1340.

[6] Shane M W, De Vos M, De Roock S, Lambers H (2003). Shoot $\mathrm{P}$ status regulates cluster-root growth and citrate exudation in Lupinus albus grown with a divided root system. Plant Cell and Environment, 26: 265-273.

[7] Li H G, Shen J B, Zhang F S, Tang C X, Lambers H (2008). Is there a critical level of shoot phosphorus concentration for cluster-root formation in Lupinus albus? Functional Plant Biology, 35: 328-336.

[8] Raghothama K G (1999). Phosphate acquisition. Annual Review of Plant Physiology and Plant Molecular Biology, 50

\section{(1): 665-693.}

[9] Hodge A. Roots: The acquisition of water and nutrients from the heterogeneous soil environment. Lüttge U, Beyschlag W, Büdel B, Francis D, Eds. Progress in Botany. Berlin: Springer-Verlag, 2010, pp. 307-337.

[10] Zhang S G, Liu G D, Dou Y Q, et al. (2002). Effects of low-phosphorus and drought stresses on growth of wheat (Triticum aestivum). Acta Botanica Boreali-Occidentalia Sinica, 22 (3): 574-578.

[11] Garg B K, Burman U, Kathju S (2004). The influence of phosphorus nutrition on the physiological response of moth bean genotypes to drought. Journal of Plant Nutrition and Soil Science, 167: 503-508.

[12] Jin J, Wang G H, Liu X B, et al. (2005). Phosphorus application affects the soybean root response to water deficit at the initial flowering and full pod stages. Soil Science and Plant Nutrition, 51 (7): 953-960.

[13] Zhao C H, Pang H C, Li Y Y (2009). Effect of interaction of water and phosphorus on maize growth and phosphorus accumulation in fluvo-aquic soil. Plant Nutrition and Fertilizer Science, 15 (1): 236-240.

[14] Qiao Z J, Cai K Z, Luo S M (2011). Interactive effects of low phosphorus and drought stress on dry matter accumulation and phosphorus efficiency of soybean plants. Acta Ecologica Sinica, 31 (19): 5578-5587.

[15] Song C J, Ma K M, Qu L Y, et al. (2010). Interactive effects of water, nitrogen and phosphorus on the growth, biomass partitioning and water-use efficiency of Bauhinia faberi seedlings. Journal of Arid Environments, 74: 1003-1012.

[16] Lu R K. Methods of soil agricultural chemical analysis. Beijing: China Agriculture Sci-tech Press, 2000.

[17] Hermans C, Hammond J P, White P J, et al. (2006). How do plants respond to nutrient shortage by biomass allocation? Trends in Plant Science, 11: 610-617.

[18] Songsri P, Jogloy S, Vorasoot N, et al. (2008). Root distribution of drought-resistant peanut genotypes in response to drought. Journal of Agronomy and Crop Science, 194: 92-103.

[19] Feng G L, Liu C M. Wang L (1996). Roles of soil water in regulating root growth and distribution. Eco-Agriculture Research, 3: 7-11.

[20] Jungk A, Barber S A (1974). Phosphate uptake rate of corn roots as related to the proportion of the roots exposed to phosphate. Agronomy Journal, 66: 554-557.

[21] Sorgona A, Abenavoli M R, Gringeri P G, et al (2007). Comparing morphological plasticity of root orders in slow- and fast-growing citrus rootstocks supplied with different nitrate levels. Annals of Botany, 100: 1287-1296.

[22] He Y Q, Fan J B, Li C L, et al. (2011). Effect of soil moisture and phosphorus application on concentration of available phosphorus in red soil under aerobic rice cultivation. Acta Pedologica Sinica, 48 (6): 1196-1202.

[23] He Y Q, Shen Q R, Kong H M, et al. (2003). Effect of soil moisture on phosphorus contents of red soil under rice cultivation in aerobic soil condition. Journal of Soil and Water Conservation, 17 (2): 5-8. 
[24] Lou Y S, Li Z P, Zhang T L (2005). Change in available P content in paddy soils as affected by phosphorus fertilization and soil moisture regime. Soils, 37 (6): 640-644.
[25] Tang H L, Shen J B, Zhang F S, et al.(2013). Interactive effects of phosphorus deficiency and exogenous auxin on root morphological and physiological traits in white lupin (Lupinus albus L.). Science China Life Sciences, 56 (4): 313-323. 